\title{
Study on the Reliability of Music as a Stimuli Focus During Driving by using Event Related Potential
}

\author{
Mai Mariam Mohamed Aminuddin \\ Centre for Telecommunication Research \& Innovation \\ Fakulti Kejuruteraan Elektronik Dan Kejuruteraan Komputer \\ Universiti Teknikal Malaysia Melaka \\ Malaysia
}

\begin{abstract}
Focus on the definition of physiology in one of several instances of concurrent ideas requires the possession of the mind which means to dispose of certain items to effectively handle others. In order to avoid road collisions, concentrating on driving is very necessary. In this study, drivers' focus was analyzed by their driving performance recorded by N170 wave of electrical evoked potential and driving score from the simulator. Subjects were stimulated by the radio talk, music and no sound (silent) in three separate recordings. The results show that music did not help to keep the driver's focus on the road. This finding could be useful for a long-distance traveller as well as to develop a methodology to avoid the focus deficit while driving.
\end{abstract}

Keywords: Focus loss, Electrical Evoked Potential, Drowsiness, Driving safety.

\section{INTRODUCTION}

Accidents involving road traffic lead to injuries and fatalities that affect people, families and communities. It places a burden on the healthcare delivery system by occupying restricted hospital beds and using funds, as well as resulting in loss of productivity and earnings, with social and economic implications. From the year 2007 to 2011, Malaysia loses more than RM10 Million owing to road accidents. Statistics and study from the Malaysian Institute of Road Safety Research (MIROS) recorded 7,000 fatalities each year as a result of road accidents and ranked third among other death causes [1]. Malaysia, behind Thailand and Vietnam, has the third-largest death rate from road traffic accidents in Asia and ASEAN in 2016 [2].

A research by the University of Bordeaux in France revealed that 52 percent of the nearly 1000 drivers wounded in an accident reported drifting attention before their vehicles crashed [3]. Scientists say the issue that is also recognized as the syndrome of the white line occurs when those behind the wheel begin to dream or get caught up on the radio. This study is essential, particularly in Malaysia, as road accident increases due to absence of alertness while driving [4]. Drivers generally listen to the music to overcome boredom and stay awake, particularly if they are traveling alone. However, in their melody and lyrics, music has elements of repetition [5]. Repetition is the finest element that causes a deficit of focus.

\section{RELATED WORK}

Focus deficit could be measured by using electroencephalogram (EEG). The EEG is the signal

\author{
Haslinah Mohd Nasir \\ Centre for Telecommunication \& Innovation \\ Fakulti Teknologi Kejuruteraan Elektrik Dan Elektronik \\ Universiti Teknikal Malaysia Melaka \\ Malaysia
}

commonly used to detect the epileptic seizures, which are the result of abnormal electrical activity in the brain [6]. EEG provides a method to investigate the general function of the brain, including its reaction to particular stimuli that will be represented as changes in the EEG, globally known as eventrelated potentials (ERP). ERP is an electrical potential recorded from a human or other animal's nervous system following stimulus presentation, reaction. Based on prior studies [7] and [8] significance decreases in electrical evoked has been reported in the presence of repetition.

In this study, the feasibility of music to overcome focus loss is analyszed by combining two results of driving performance i.e., the recording of the driver's EEG and driving score from the simulator. Concerning EEG, based on [9] N170 wave element is the best to analyze to evaluate driving attention while listening to music and radio talk as well as silent stimulation, respectively. The results could be useful information for the in the long-distance traveler.

\section{METHODOLOGY}

This experiment was attended by a total of 15 participants aged between 18 and 25 years with a valid driving license. All volunteered are students of Universiti Teknikal Malaysia Melaka. Before participating in the experiment, all participants signed informed consent and confirmed in healthy and fresh conditions to ensure no other influence except natural attention loss if occur.

The experiment setup is shown in Fig. 1. This experiment uses a driving simulator Carnetsoft. In a semi-circle, three monitors were arranged to offer a 3-D visual. The driving simulator has a periodic steering wheel size, clutch-petrol-brake pedal, gear stick and signal pedal. The Carnetsoft driving simulator records the driving errors and accidents and behavior of subject participant as shown in Fig. 2. The EEG recording environment comprises a BIOPAC Inc biosignal amplifier scheme, MP150 EEG 100C and computer software (Acknowledge 4.2) as well as a surveillance device. At $500 \mathrm{~Hz}$, the EEG was sampled. The electrodes ( $\mathrm{Ag} / \mathrm{AgCl})$, the upper lip (adverse electrode) and the vertex $(\mathrm{Cz})$ for grounding are positioned on the left and right occipital. The recording takes place in a light-off and soundproof space. Lights were off because noises from lamps could influence the EEG recording and to avoid visual disruption.

Simulations had 3 parts. Duration of each was about 25 minutes and between parts there was 5 minutes break. A road 
with moderate traffics scenario was performed on the monitor in all parts. Each part had different scenario as to avoid indirect endogenous stimulation to the participants.

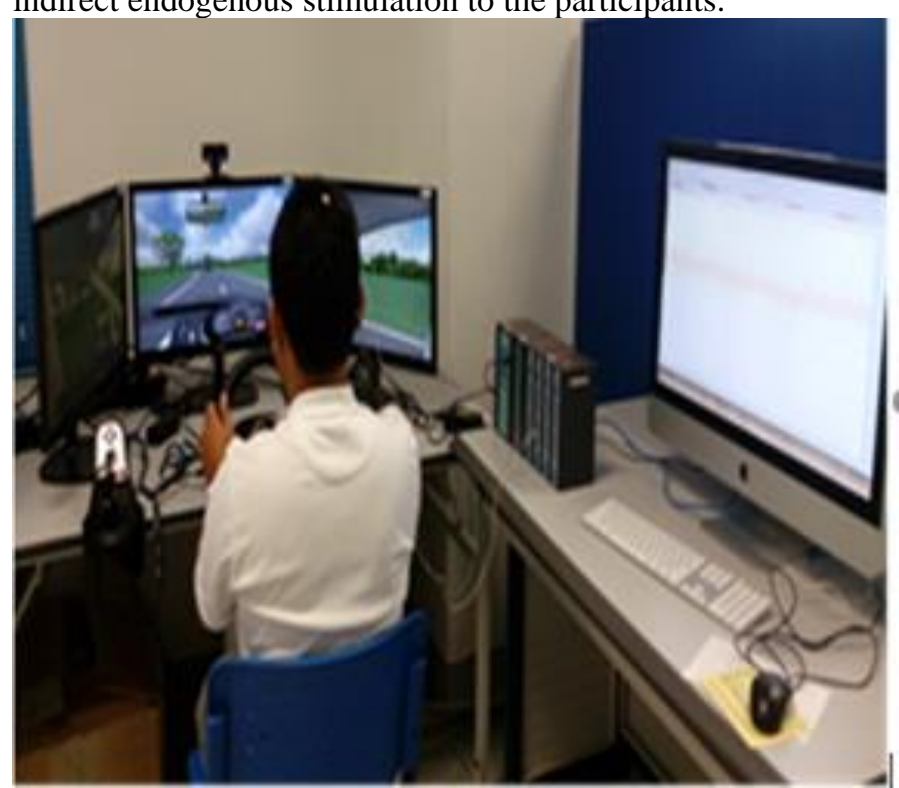

Fig. 1. This figure shows the driving stimulator and experimental setup.

In the first part, no sound (control information) was triggered to the participants. Except for traffic and vehicle noise, they drove in' quiet' condition. In the second part, participants drove with music played through the headphone. The music is their choice of music which they normally hear when they are driving. The music can be with lyric or instrumental. In the last part, a talk radio program without song (deejay chatting with the radio caller or the guest) were used for stimulation. The EEGs were analyzed offline. They are filtered with a digital bandpass filter $(1-30 \mathrm{~Hz})$ to achieve active and focused alpha and beta waves, By using threshold detection (amplitude greater than $50 \mu \mathrm{V}$ ), sweeps containing artifacts were dismissed. At each post-stimulus of $1 \mathrm{~s}$, they were segmented. Each participant received at least 500 responses from the recording.

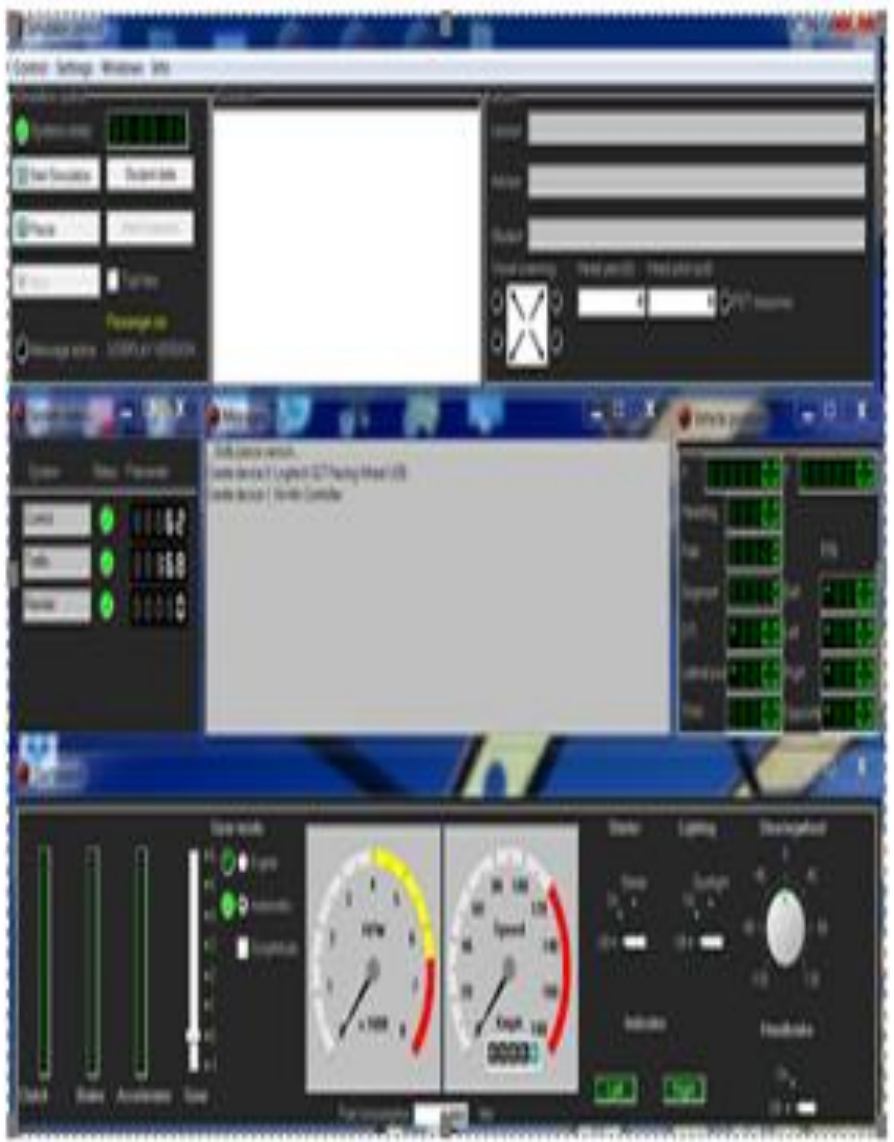

Fig. 2 Driving simulator interface that recorded all performances of the driver

\section{RESULTS AND DISCUSSION}

Grand averaged results of all 15 participants are presented in respective stimulation types. Fig. 3, Fig. 4 and Fig. 5 show the amplitude of N170 wave over responses for all stimulations, respectively. The amplitude of N170 ERP is proven in previous studies [8] [9] that the amplitude of ERPs over time are almost constant or increase if the participants focus on the task. The jitter and unstable look of amplitudes are noises but EEG signal is very small. Noises were already discarded by using the averaging technique. EEG signal is very sensitive, and the scale is in microvolt hence the changing of amplitude between immediate responses looks big. However, overall, the pattern of amplitude decrement can be seen clearly as in Fig. 3. It shows the grand averaged results of silent stimulation. It is observed that the amplitude of the N10 wave decreases over time. This suggests that the focus of the driver easily declined when there is no stimulation given. It is observed that the amplitude of the N10 wave decreases over time. As expected, for music stimulation as shown in Fig. 4, a similar decrement of N170 amplitude is found in all subjects. However, for the radio talk stimulation, see Fig. 5, the amplitude of the N170 wave is almost constant over responses. This consistent with the finding by Jonsson and Dahlback [10], where they found that the combination of submissive and dominant speech helps to boost the driving performance. 


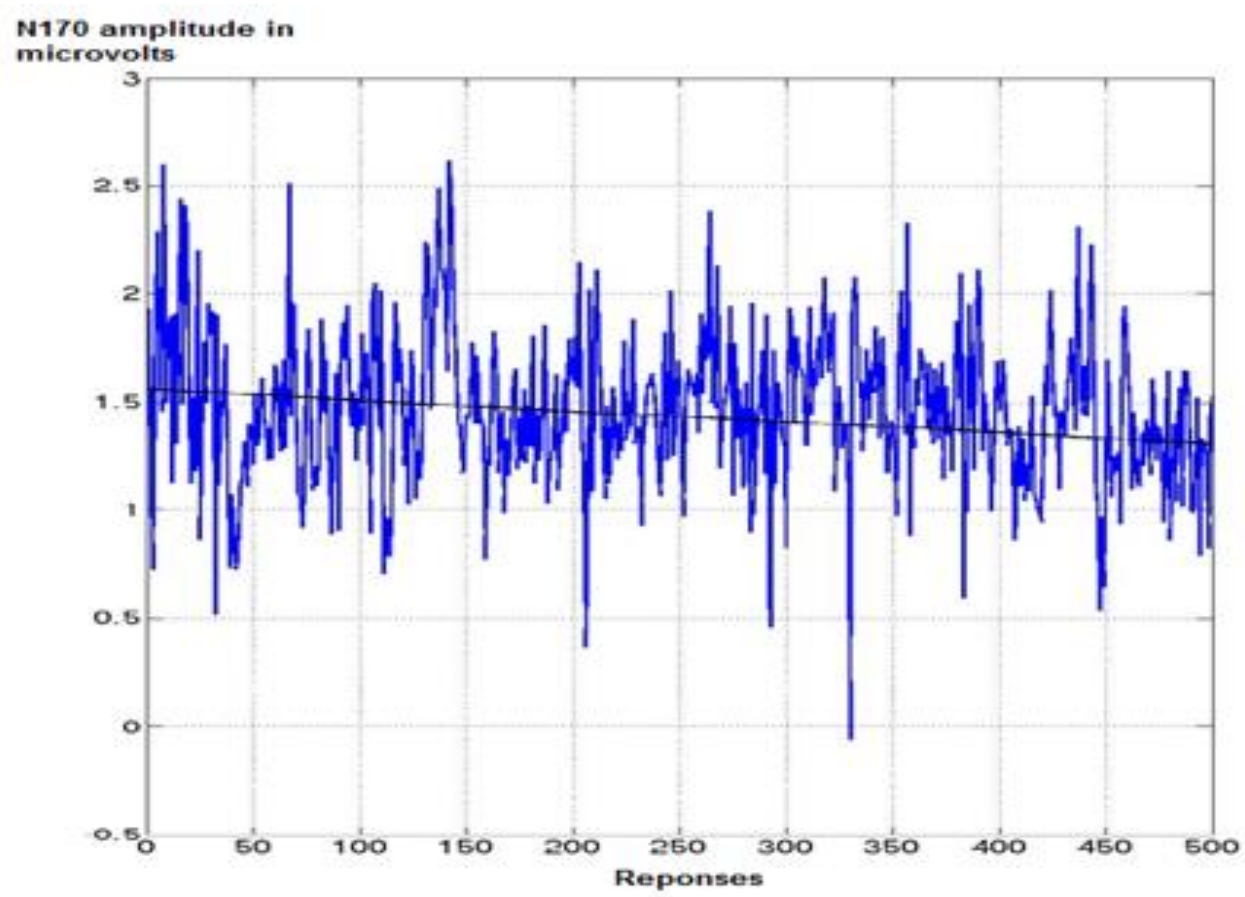

Fig. 3 Grand averaged of all participants for silent stimulation. The regression line shows decrement pattern of waveform.

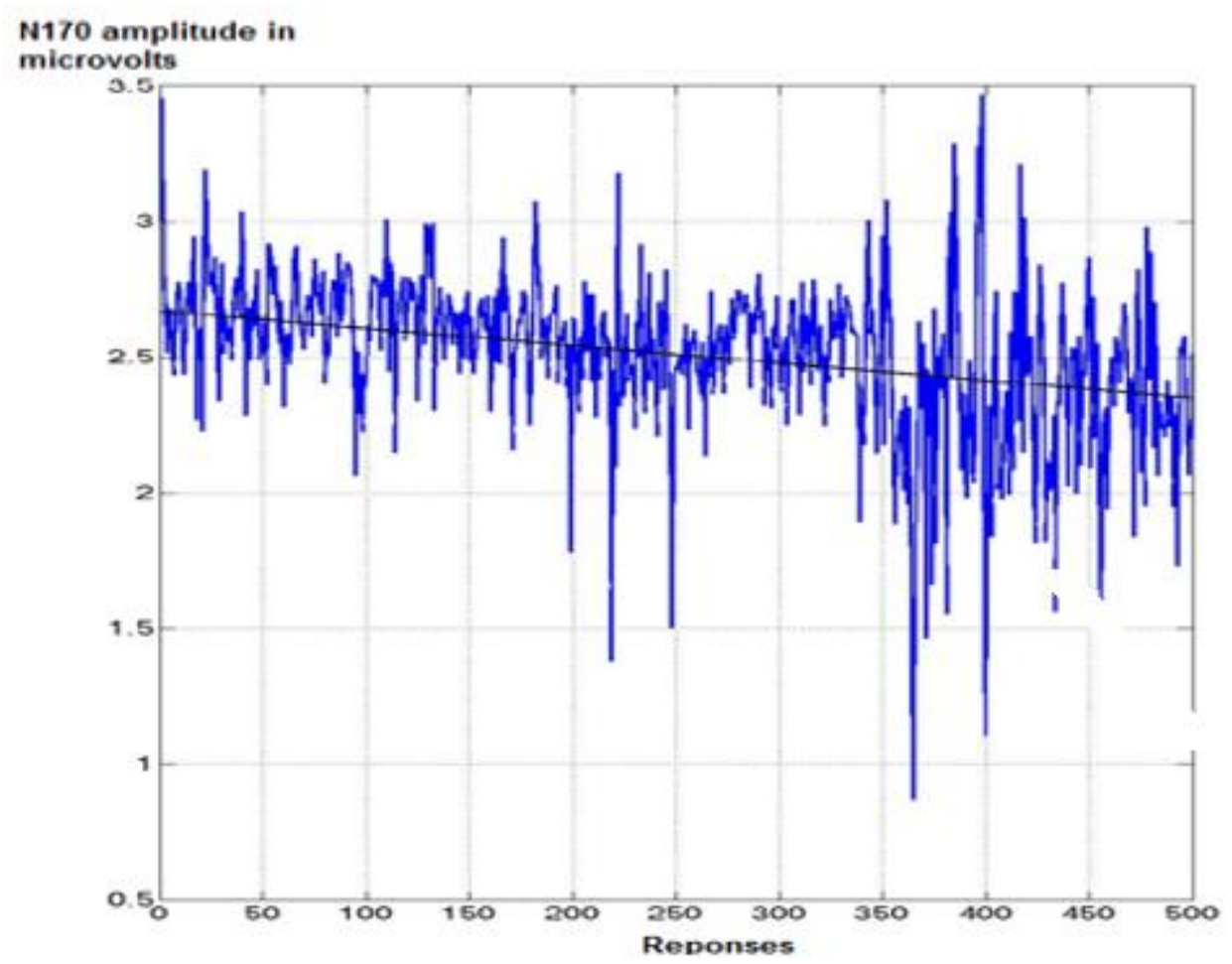

Fig. 4. Grand averaged of all participants for music stimulation. The regression line shows decrement pattern of waveform. 


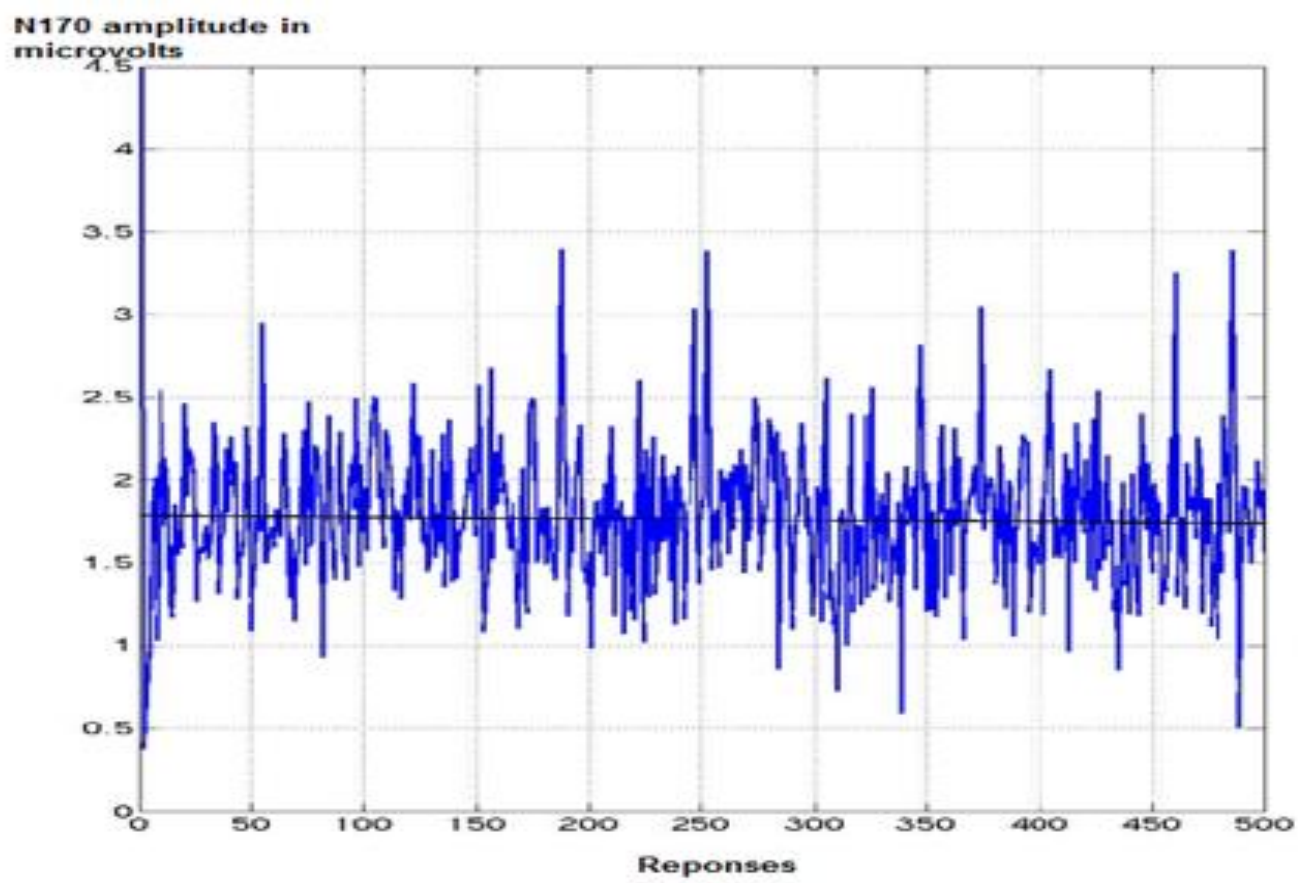

Fig. 5. Grand averaged of all participants for radio talk stimulation. The regression line shows that the waveform is constant.

The performance of the driving recorded by the simulator is translated in a form of driving score. It calculates the percentage of accidents and warning due to unsafe action such as driving outside the line, driving dangerously or breaking traffic laws that occur throughout the driving. From the driving score results, as shown in Table 1, the average of warnings and accidents in percentage are high when the driver listens to music and in silent condition. However, a very few warnings and accidents were found when the driver listen to radio talk. These results suggest that the drivers are more focus on the road if they listen to radio talk compared to when listening to music.

TABLE 1. GRAND AVERAGE RESULTS OF DRIVING SCORE.
\begin{tabular}{|c|c|c|}
\hline Stimulus & \% Warning & \% Accident \\
\hline Silent & $25.0 \%$ & $65.6 \%$ \\
\hline Music & $35.0 \%$ & $49.0 \%$ \\
\hline Radio talk & $4.3 \%$ & $7.7 \%$ \\
\hline
\end{tabular}

Talking is one of the important sound sources. Talking may affect human driving efficiency. Mark Vollrath's study [11] showed that when listening to the passengers' small talk, debate, and voice, drivers had less chance of collision. This means the drivers become more sensitive to driving while they listen to it.

Repetition is detected in music from all over the world [12]. A simple "strophic" pattern is evident in much music, in which a single sentence or phrase is repeated. When sung, the use of different words is usual for successive repetitions, as is the case with strophic lines. It is also common, however, to hear the same words used with every repetition Based on the findings, it is highly suggested that music is not the best stimulant to overcome boredom and avoid getting drowsiness while driving. Radio talk has up and down tones and pitches which give deviant in a strain of stimulation and block the occurrence of habituation (attention deficit) to the stimulus.

\section{CONCLUSION}

As disclosed in the outcome and discussion section, this article showed that listening to the music does not help to stay focus on driving task. However, listening to radio talk while driving generally allows driving efficiency to be maintained or increased. Hence, it's a nice diversion to listen to radio talk program to maintain the driver's mind on the highway instead of listening to music.

\section{ACKNOWLEDGMENT}

Authors express their sincere thanks to the Universiti Teknikal Malaysia Melaka for the support.

\section{REFERENCES}

[2] A. Abidin, S. Faudzi, F. Lamin and A. Manap, "MIROS Crash Investigation and Reconstruction Annual Statistical Report 20072011," MIROS, 2012.

[3] M. Taylor, "The Driving Habit You Need To Break," 2012. [Online] Available:

https://www.prevention.com/life/a20439030/daydreaming-anddriving-can-cause-accidents/. [Accessed 20 April 2020].

[4] J. He, E. Becic, Y. C. Lee and J. McCarley, "Mind Wandering Behind the Wheel: Performance and Oculomotor Correlates Human Factor," The Journal of the Human Factors and Ergonomics Society, vol. 53, no. 1, pp. 13-21, 2011.

[5] B. Benward and M. Saker, Music in Theory and Practice, 1 ed., McGraw Hill, 2011 
[6] M. Shah, S. Saurav, R. Sharma and R. Pachori, "Analysis of Epileptic Seizure EEG Signals Using Reconstructed Phase Space of Intrinsic Mode Functions," in Conference on Industrial and Information System, Gwalior, 2014.

[7] M. A. Aminuddin and I. Mustaffa, "The effect of Sound Levels on Attention Deficit," in International Conference on Instrumentation, Communication, Information Technology and Biomedical Engineering, 2013.

[8] M. M. M. Aminuddin, H. M. Nasir, I. Mustaffa and A. M. Othman, "Objective Verification of Focus," 2015.

[9] H. M. Nasir, M. M. M. Aminuddin, N. Brahin and I. Mustaffa, "Event Related Potential N100 vs N170 Wave Results Comparison on Driving Alertness," Journal of Engineering Science and Technology, vol. 14, no. 3, pp. 1150-1160, 2019.

[10] I. Jonsson and N. Dahlback, "Driving with a Speech Interaction System: Effect of Personality on Performance and Attitude of Driver.," Heraklion, Crete, Greece, 2014.

[11] M. Vollrath, "Speech and Driving Solution or Problem.," Institute for Transportation Research, German Aerospace Center (DLR), 2007.

[12] B. Nettl, The Study of Ethnomusicology: Thirty-One Issues and Concepts., Urbana: University of Illinois Pres, 2005. 